\title{
O (RE)CONHECIMENTO DA SÓCIO-HISTÓRIA NAS CAPACIDADES DE SIGNIFICAÇÃO: CONCEITOS NECESSÁRIOS PARA OPERACIONALIZAÇÃO DE LINGUAGEM E DIDATIZAÇÃO DE GÊNEROS
}

\author{
SOCIO-HISTORICAL RECOGNITION IN SIGNIFICATION \\ CAPACITIES: CONCEPTS NEEDED TO OPERATIONALIZE \\ LANGUAGE AND FOR RENDERING TEXT GENRE \\ INTO A DIDACTIC TOOL
}

\section{Everton Gelinski Gomes de Souza* Lidia Stutz ${ }^{* \star}$}

\section{RESUMO}

O presente artigo visa discutir a respeito da operação de linguagem denominada (re) conhecimento da sócio-história do gênero, apresentada por Cristovão e Stutz (2011) no quadro das capacidades de significação. Nesse sentido, demonstramos os traços textuais utilizados para analisar essa operação de nível macrocontextual, relacionada com a atividade geral de linguagem, portanto, externa ao texto. Para tanto, enfocamos duas produções do gênero borror short story tomadas como diagnóstico discursivo. A primeira foi desenvolvida por um(a) aluno(a) de uma turma de $9^{\circ}$ ano, numa escola da cidade de Guarapuava/

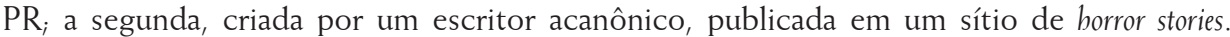
Adotamos como fundamentação teórica pressupostos do interacionismo sociodiscursivo (BRONCKART, 1999) que nos permitem repensar o gênero textual e sua relação com as ações de linguagem e as atividades sociais sob o prisma da significação. Do mesmo modo, pautamo-nos, principalmente, em estudos de Cristovão e Stutz (2011) sobre a proposta das capacidades de significação; em Stutz (2012) e Souza (2015) que discorrem sobre a relação entre essas capacidades e sua importância para compreendermos a constituição da atividade geral de linguagem e, de que maneira a sócio-história pode estar imbricada num determinado gênero de texto. Os resultados evidenciam que a operação de linguagem estudada é um protocolo cognitivo que desenvolve a capacidade de reconhecimento, assim como de regulação sobre valores e normas sociais, sobre a constituição dos simbolismos, dos jogos ideológicos que se materializam nos protótipos discursivos, e, dessa forma, o (re)

\footnotetext{
* Universidade Estadual do Centro-Oeste, UNICENTRO, Guarapuava, PR, Brasil. evertonton motreve@yahoo.com.br Orcid: https://orcid.org/0000-0002-0476-9672

** Universidade Estadual do Centro-Oeste, UNICENTRO, Guarapuava, PR, Brasil. lidia.stutz@ gmail.com

Orcid: https://orcid.org/0000-0002-8173-2769
} 
conhecimento da sócio-história outorga a ligação entre as representações e seus referentes na estrutura discursiva.

Palavras-chave: capacidades de significação; (re)conhecimento da sócio-história, horror short story.

\section{ABSTRACT}

This paper aims to discuss the operation of language titled socio-history recognition of the text genre, presented by Cristovão and Stutz (2011) within the framework of the signification capacities. Thus, we demonstrate the text traces used in order to analyze such operation of macro context level, which is related to the language general activity and, consequently, external to the text. Towards this end, we focus two productions of the horror short story genre taken as discursive diagnosis. The first one was developed by a $9^{\text {th }}$ year pupil from high school in Guarapuava/PR; second one was created by a non-canonical writer and published in a horror stories website. Concerning to theoretical foundation, we are based on the studies of socio-discursive interactionism (BRONCKART, 1999), which discuss text genre and its relation to the actions of language and social activities under the lights of signification. Likewise, and mainly, we focus on studies of Cristovão and Stutz (2011) about proposing capacities of signification; on Stutz (2012) and Souza (2015) that address the relation between such capacities and its value for understanding language general activity, and in what way socio-history may be embedded in a particular text genre. Results reveal that socio-historical recognition is a cognitive protocol, which is responsible for developing capacities of recognizing and regulating values and social standards, constitution of symbolism, ideological frames materialized into discursive prototypes and, therefore, this operation of language grants connection between representations and their referents in the discursive structure.

Keywords: signification capacities; socio-historical recognition; horror short story.

\section{INTRODUÇÃO}

O papel formador do ensino de línguas constitui um desafio pela necessidade de desenvolver práticas que contemplem a complexidade da linguagem em situações de circulação social. Esse fator, embora previsto em documentos norteadores ${ }^{1}$ por meio da abordagem de gêneros de texto como cerne do trabalho do professor de línguas, demanda maiores reflexões para os encaminhamentos teóricometodológicos para o ensino de língua inglesa na escola brasileira. Nesse sentido, nos aliamos à proposta de ensino de gêneros como megainstrumentos, propiciadores de aptidões necessárias para o seu domínio, sendo estas denominadas de capacidades de linguagem (SCHNEUWLY, 2004; DOLZ; PASQUIER; BRONCKART, 1993).

Com vistas nessas questões, pontuamos o crescimento considerável de estudos advindos da Didática das Línguas, em contexto suíço-francófono e em

1. Como exemplo, as Diretrizes Curriculares do Estado do Paraná (2008) e a Base Nacional Comum Curricular (BRASIL, 2018 ). 
Linguística Aplicada em nosso contexto, os quais preconizam o desenvolvimento de estratégias centralizadas no suporte e aprimoramento das práticas docentes. Como exemplo, citamos Machado e Cristovão (2009); Costa-Hübes e Simioni (2014); Cristovão et al (2015) que discutem os gêneros textuais para apreensão de conhecimento no meio escolar, a partir de questões como criação de modelos didáticos, de sequências didáticas ${ }^{2}$ e de capacidades de linguagem para o ensino de línguas.

As capacidades de linguagem, segundo Cristovão (2007), são definidas como conjuntos de operações de linguagem responsáveis pela produção e compreensão textual, de ordem oral ou escrita, as quais são essenciais para o desenvolvimento humano, dadas as relações que exercem entre si a partir de práticas de linguagem. Apesar do papel primário dessas capacidades em meio à relação dialógica entre os sujeitos e o mundo semiótico ao qual pertencem, há ainda a necessidade de elocubrações sobre as capacidades de significação, pois estão relacionadas diretamente com o processo de inteligibilidade sobre dimensões que perpassam níveis ideológico e cultural, bem como aspectos sócio-históricos mais amplos. Sob esse prisma, observamos que esses níveis de materialização da linguagem permanecem ainda silenciados no ensino, ocasionando lacunas no processo de letramento.

Assim, neste estudo analisamos as capacidades de significação em produções escritas de horror short stories, haja vista a necessidade de se elucidar as operações de linguagem previstas por Cristovão e Stutz (2011) em termos de análise, descrição e transposição dos conceitos adotados pelas autoras, sobretudo, no que diz respeito ao ensino e aprendizagem. Consideramos pertinente essa discussão para o fortalecimento do trabalho do professor de línguas, de pesquisadores e, em nosso caso particular, pela necessidade de recobrar as capacidades de significação e de demonstrar suas implicações no nível geral e mais amplo da atividade de linguagem.

Para tanto, o artigo apresenta como plano global cinco seções: primeiramente a introdução aqui exposta; segundo, a fundamentação teórica com base no Interacionismo Sociodiscursivo e as capacidades de significação; terceiro, a metodologia voltada à natureza, objetivo, contexto e operação analisadas das capacidades de significação; quarto, a análise de dados das operações do (re)

2. Modelo e sequência didática são noções que advêm do trabalho proposto por Schneuwly e Dolz (2004), no qual a primeira corresponde ao estudo sistemático dos gêneros textuais, no inuito de se compreender o funcionamento desse artefato; a segunda é um instrumento que comporta uma sequência de atividades baseadas no gênero de texto, criadas a partir do processo de transposição didática realizada com base no modelo didático. 
conhecimento da sócio-história do gênero nas capacidades de significação; e a quinta seção apresenta breves considerações finais.

\section{FUNDAMENTAÇÃO TEÓRICA}

\subsection{Interacionismo Sociodiscursivo, gêneros e capacidades de linguagem}

O interacionismo sociodiscursivo (ISD) (BRONCKART, 1999; 2006) representa um arcabouço teórico que encontra nas atividades de linguagem a chave mestra para a compreensão das condutas de cunho sócio-histórico e ideológico que o ser humano apresenta. Essa premissa solidifica-se numa base em que a linguagem é vista como instrumento de comunicação e, por conseguinte, o fio articulador de saberes entre indivíduos situados em atividades sociais de variadas naturezas.

Do mesmo modo, é plausível a atribuição de caráter metodológico ao ISD, uma vez que, segundo Machado (2005), propõe a análise da linguagem em sua manifestação concreta, consolidada em gêneros textuais, os quais abarcam em seu âmago a expressão individual, coletiva e a singularidade comunicativa oriunda das atividades de linguagem. Nesse caso, essa singularidade comunicativa é representada pelo tema, que influi nas escolhas verbais e não verbais que um ato comunicativo exige, ao passo que a atividade de linguagem é caracterizada como qualquer atividade realizada num âmbito social, por intermédio da linguagem, traçada a partir de objetivos e ideologias específicas, com carga histórica sob movimentos sincrônicos e diacrônicos.

Assim, a ontogênese do desenvolvimento humano pode ser observada a partir da tríade composta pela atividade social, linguagem e indivíduos, na qual os gêneros textuais exercem papel fundamental entre esses elementos, e, num viés dialógico, asseguram a inteligibilidade discursiva. Conforme Bronckart (2016),

os gêneros textuais constituem a organização ou a forma concreta das atividades de linguagem cuja indexação se alia aos conteúdos e às situações comunicativas relativamente específicas. Nesse sentido, as atividades de linguagem evidenciam a dependência em relação aos conteúdos e às situações conforme elas se apresentam em um espaço social particular (p.136, tradução nossa) $)^{3}$.

3. [...] les activités langagières prennent la forme concrète de genres de textes qui sont indexés à des contenus et à des situations communicatives plus ou moins spécifiques et qui témoignent d'une dépendance à l'égard de ces contenus et de ces situations, tels qu'ils se présentent dans un espace social particulier (BRONCKART, 2016, 136). 
Os gêneros de texto irão, portanto, materializar as condutas verbais oriundas dessas atividades, de modo que tanto a unidade de comunicação ${ }^{4}$, ou seja, o texto, quanto os parâmetros contextuais instituam uma forma discursiva relativamente estável, tornando legível o fim a que se destina.

Dada essa questão, é pertinente ressaltar que a inteligibilidade dos gêneros decorre de operações cognitivas específicas, concebidas como capacidades de linguagem. Para Dolz, Pasquier e Bronckart (1993), elas compreendem, parcialmente, um mecanismo de reprodução de modelos discursivos. Desse modo, pode-se dizer que o meio pelo qual os seres humanos são capazes de compreender a arquitetura do discurso, a imbricação de intenções e objetivos e as formas de agir estão diretamente ligados a essas capacidades.

Em estudos de Schneuwly e Dolz (1997), por exemplo, há ênfase na centralidade da noção de gênero de texto como um propulsor social e externo de faculdades enunciativas individuais, transformadas à medida que as capacidades de linguagem dos indivíduos são motivadas em conjunturas de produção e compreensão, tanto oral quanto escrita. Em termos de faculdades enunciativas, Cristovão (2009) define as capacidades de linguagem como um conjunto de operações de linguagem, responsáveis pelo processo de identificação e escolha de parâmetros textuais coerentes com as atividades de linguagem e os respectivos agires.

Cabe ressaltar que as funções psíquicas descritas sobre as capacidades de linguagem estão relacionadas a quatro diferentes desdobramentos. $\mathrm{O}$ primeiro trata das capacidades de ação, as quais permitem que o indivíduo relacione as ações realizadas verbalmente "às diversas exigências do meio social" (DOLZ, PASQUIER, BRONCKART, 1993, p. 30, tradução nossa) $)^{5}$, e assim, estão intrinsecamente ligadas ao reconhecimento de parâmetros contextuais da atividade linguageira imediata (STUTZ, 2012; SOUZA, 2015).

O segundo está ligado às capacidades discursivas, cujas operações acionam a identificação de modelos discursivos disponíveis em ambientes linguageiros (DOLZ, PASQUIER, BRONCKART, 1993), caracterizados tanto por marcadores linguísticos relativamente específicos que retratam porções da unidade comunicativa, como é o caso dos tipos de discurso (BRONCKART, 2004), quanto pela sequencialidade enunciativa e demais marcadores organizacionais dessa unidade.

$\mathrm{O}$ terceiro corresponde às capacidades linguístico-discursivas, inerentes à planificação do discurso (DOLZ, PASQUIER, BRONCKART, 1993), a outorga da coesão e coerência textuais, decorrentes da escolha adequada de mecanismos

4. O termo unidade de comunicação refere-se ao texto de um gênero (BRONCKART, 1999).

5. aux diverses exigences de son milieu social. (DOLZ, PASQUIER, BRONCKART, 1993, p. 30). 
enunciativos e de textualização (CRISTOVÃO; STUTZ, 2011) que emanam do sistema verbal complexo que é a língua em situação de uso. Trata-se de capacidades que operacionalizam a relação entre a materialização dos significados diversos e as escolhas linguísticas contextuais dados os elementos dispostos na superfície do texto.

Um quarto desdobramento já proposto por Cristovão e Stutz (2011) e Cristovão (2013) corresponde às capacidades de significação, que alia-se às três capacidades anteriores e que só é possível compreender a partir da tessitura das capacidades com o contexto mais amplo. Na próxima seção, nos debruçamos sobre a conceituação e os encaminhamentos.

\subsection{Capacidades de significação}

Mas afinal, o que é a significação? Conforme Dias (2014) expõe no Glossário Ceale, ela contempla o ato de significar, que nas raízes latinas é tornar algo inteligível por meio de sinais. Por esse ângulo, a inteligibilidade de que se trata é lançada numa esfera em que os sentidos decorrem de um sistema de simbolismo que é ao mesmo tempo cultural, social e situado, tratado aqui como língua. Desse sistema, decorrem diferentes expressões que orientam a nossa visão sobre aquilo que se representa socialmente, mas a produção de sentidos depende do quão imersos nesse simbolismo estamos e o quanto fomos orientados para as diferentes realidades que nos cercam. Diante disso, Dias (2014) atenta para a necessidade de se ampliar a noção de sinais pelas diversas facetas que permeiam a significação e afirma que a própria complexidade da língua demanda essa tarefa. Assim, a significação vai além da dicionarização de palavras e sob o olhar da enunciação alia-se aos elementos contextuais.

A significação também possui natureza ideológica, social e histórica. Essas características são identificadas no processo de formação dos saberes coletivos, os quais denotam diferentes graus de representações, à medida que os seres humanos, em sua dinamicidade, lêem e escrevem sobre o mundo com base no estatuto da heterogeneidade que apresentam as diferentes formações discursivas. Bronckart (1987, p. 48), por exemplo, explicita que "no quadro de uma ação de linguagem determinada, a constituição das significações se opera, de um lado, pela ativação de certas representações do referente; e de outro lado, pela organização de suas representações na estrutura discursiva" (tradução nossa) ${ }^{6}$.

6. Dans le cadre d'une action langagière déterminée, la constitution des significations s'opère par 'l'activation de certaines représentations du réfèrent d'une part, par l'organisation de ces représentations dans la structure discursive d'autre part. (BRONCKART, 1987, p.48). 
Nessa linha de raciocínio apresentada, a operacionalização de normas, valores e regras do mundo social torna-se um dos objetos da significação. Essa operação, por sua vez, consagra a representação da linguagem em eventos sociais, ao mesmo passo que evidencia efeitos de comunicação de eventos anteriores. A significação ocorre ainda por meio do (re)conhecimento das representações impressas em protótipos discursivos mobilizados nesses eventos, consolidados por suas normas, valores ou regras que pairam numa espécie de arquitexto, concebido como nebulosa sóciohistórica do gênero de texto (BRONCKART, 1999). Assim, conforme Bronckart (1987, p. 49),

a significação de uma unidade de discurso pode, portanto, ser definida como uma representação verbal do mundo, pertinente e legítima, que foi ativada sob o controle dos valores de interação social e que sofreu os efeitos de sua inserção em um arquétipo discursivo, a uma posição determinada no plano do texto ${ }^{7}$ (tradução nossa).

Num ponto de vista psicológico da linguagem, a própria relação predicativa descrita por Vygotsky (1987/2008) entre o pensamento e a construção da significação do objeto social por meio do signo, num primeiro momento, nos auxilia na compreensão dessa capacidade de operacionalização da linguagem como um processo intersubjetivo. Nesse sentido, conforme o próprio autor descreve, há um deslocamento gradativo do funcionamento do plano intersubjetivo para o funcionamento individual, ou seja, as faculdades mentais de legitimação dos sinais que emitem as ações do meio social são as mesmas capazes de transformar essas ações e suas significações em reguladores, os quais servirão de norte para o próprio comportamento e reconhecimento individuais.

Ao pensarmos no papel da significação mediante o processo de didatização, e, instrumentalização dos gêneros textuais para fins de ensino e aprendizagem de línguas (DOLZ; NOVERRAZ; SCHNEUWLY, 2004; CRISTOVÃO, 2009), ancoramo-nos nas capacidades de linguagem de nível macrocontextual, nomeadas como capacidades de significação (STUTZ; CRISTOVÃO, 2011; CRISTOVÃO, STUTZ, 2011; STUTZ, 2012; CRISTOVÃO, 2013; SOUZA, 2015). Nesse sentido, as capacidades de significação correlacionam as operações de conexões globais com as atividades do meio social em domínios semânticos abalizados, intrínsecas para que a significação sobrevenha no decorrer do processo dialógico das atividades de linguagem e da materialização do discurso nos gêneros textuais.

7. La signification d'une unité du discours peut dès lors être définie comme une représentation verbale du monde, pertinente et légitime, qui a été activée sous le contrôle des valeurs de l'interaction sociale, et qui a subi les effets de son insertion dans un architype discursif, à une position déterminée du plan de texte. (BRONCKART, 1987, p. 49). 
Dessa forma, as operações de linguagem que corporificam o processo de significação são apresentadas no quadro a seguir:

Quadro 1. Operações de linguagem das capacidades de significação.

(1CS) Compreender a relação entre textos e a forma de ser, pensar, agir e sentir de quem os produz;

(2CS) Construir mapas semânticos;

(3CS) Engajar-se em atividades de linguagem;

(4CS) Compreender conjuntos de pré-construídos coletivos;

(5CS) Relacionar os aspectos macro com sua realidade;

(6CS) Compreender as imbricações entre atividades praxeológicas e de linguagem;

(7CS) (Re)conhecer a sócio-história do gênero;

(8CS) Posicionar-se sobre relações textos-contextos.

Fonte: Recorte das operações das capacidades de significação em Cristovão e Stutz (2011, p. 23).

Consideramos que as oito operações apresentadas encontram-se harmonizadas em um núcleo discursivo conciliatório, por meio das capacidades de significação, e, dessa forma, precisam aliar-se às capacidades de ação (do contexto imediato), discursivas (da configuração geral) e linguístico-discursivas (das unidades menores). Em uma analogia em níveis hierárquicos, as capacidades de significação compreenderiam o nível externo à unidade de comunicação da atividade imediata de linguagem, tendo como próximo nível interno as capacidades de ação, seguidas das discursivas, e, no menor nível, as linguísticos-discursivas.

A operação 1CS visa a compreender a relação entre textos e a forma de ser, pensar, agir e sentir de quem os produz possibilitando tecer hipóteses e resgatar elementos do mundo físico, psíquico e social das instituições, espaços, esferas da atividade de linguagem. A operação 2CS explora os mapas semânticos, que como já exposto em Stutz (2012), informa sobre os conhecimentos de ordem individual e coletiva com base nas escolhas de um campo lexical dada uma rota de informações possíveis, ou compreensão de segmentos de tratamentos temáticos. A operação 3CS abrange o engajamento na produção e compreensão da atividade de linguagem dada uma visão holística da situação contextual e textual. As operações 4CS e 5CS buscam tecer relações dos pré-construídos coletivos advindos da atividade de linguagem quanto ao contexto macro e às interações com a realidade de quem a utiliza. As operações 6CS e 8CS analisam, respectivamente, os modos de fazer advindos do olhar praxeológico com a linguagem que permeia as atividades e os posicionamentos quanto à atividade de linguagem com relação aos textos e os contextos em que atua. No rol das operações, como elemento-chave para as análises de nosso artigo, o descritor 7CS envolve o ato linguageiro de (re)conhecimento da sócio-história do gênero. 
Ao pensarmos nas questões apresentadas, incluímos a riqueza cultural como componente da sócio-história do gênero. A riqueza cultural compõe as formas representacionais das esferas de atividades dos seres humanos, como são os casos das artes, da política, da ciência, para citar alguns. Cada uma deles refrata ondas específicas de sua criatividade, conforme se observa na arte literária e, mais especificamente na literatura do horror tratada neste estudo, por exemplo, em que a significação ancora-se no simbolismo social de figuras que provocam o medo e a tensão.

Do ponto de vista cultural, por exemplo, "A Coisa" de Stephen King (2014) espelharia a figura clássica do horror, sobretudo, por lavrar características essenciais que perturbam o expectador, por meio de características psicológicas como a insanidade e a psicopatia na ideologia do enredo, pela estranheza de um ser que habita uma cidade pequena e isolada, e, além disso, pelo uso do medo e das fobias geradas na infância que perduram até a fase adulta, como mecanismo de fragilização do indivíduo e empoderamento do ser sobrenatural que atua na memória coletiva.

Por seu caráter cultural, a significação decorre de protocolos cognitivos de reconhecimento das figuras e mecanismos que se entrelaçam para produzir, no caso do exemplo citado, o horror nos indivíduos. Isso vale também para outras esferas de atuação humana. Ao longo de sua vida, cada ser humano terá acesso a inúmeros protocolos sociais de significação, e, dependente desse fator, será capaz de identificar os simbolismos e as diversas orientações para a realidade social. Muitas vezes, aquilo que se crê não é automaticamente aquilo que está validado no meio social. Érnica (2008), a partir de estudos de Vygotsky, expressa a noção de construção coletiva de saberes como uma realidade negociada, de valor social, externa a si mesma, e, para nós, compreende outro dos objetos da significação pelo que foi descrito e por seu caráter simbólico e semiótico.

Finalmente, em meio às tentativas de elucidarmos a significação enquanto operação psíquica, da mesma maneira, reiteramos seu papel potencializador das capacidades de linguagem, sendo responsável pela compreensão da natureza das representações sociais, históricas e culturais. Por tratar-se de um termo vinculado à atividade geral do ser humano (STUTZ, 2012), diferentemente da atividade imediata, as capacidades de significação permitem compreender os conjuntos de sentidos que transitam nas ideologias, nas verdades negociadas, nas ideias, solidificadas em arquétipos discursivos, do mundo real. A significação, neste estudo, tem valor terminológico similar a "znachenie", um termo geral utilizado, segundo Wertsch (1988, p. 235), para descrever a construção de sentidos, que corresponde ao fator interpretativo verbal daquilo que chamamos de atividade de linguagem. 
As capacidades de significação demandam um olhar holístico que contempla de modo amplo as atividades de linguagem. Sendo assim, buscamos mobilizar o agir por meio da linguagem no macrocontexto. Consideramos, assim como Bronckart (1987), que não há uma relação direta entre as coisas e os signos, mas que são as condições de funcionamento da linguagem que possibilitam gerar a inteligibilidade. Nessa linha de raciocínio temos o contexto imediato para construir representações sobre as ações de linguagem, ou seja, os textos, que têm nas capacidades de ação operações diversificadas com relação ao enunciador, enunciatário, objetivo, local, período de produção quanto aos mundo físico e social/subjetivo. Contudo, os aspectos do contexto macro que englobam as capacidades de significação facilmente ficam descobertos, principalmente se o enunciador/enunciatário não tiver ainda uma compreensão profunda sobre o funcionamento dos discursos, fato comum nas estudos de gêneros em sala de aula, situação na qual o professor precisa explicitar tais condições aos alunos. As capacidades de significação, portanto, são a nosso ver, a compreensão profunda dos discursos.

O arcabouço teórico apresentado servirá como alicerce neste estudo, em que adotamos uma perspectiva interacionista sociodiscursiva de análise textual (BRONCKART, 1999), lançando mão da inteligibilidade de questões relacionadas à materialização ideológico-discursiva do gênero textual, ampliando as noções apresentadas sobre os mundos físico e sociossubjetivo por Bronckart (1999; 2006; 2008), à guiza das noções de atividade geral (STUTZ, 2012) e de ideologia (BAKHTIN/VOLOCHÍNOV, 2009).

\section{METODOLOGIA}

\subsection{Natureza, objetivo e contexto de pesquisa}

Esta é uma pesquisa qualitativa, em que interpretamos a operação de linguagem das capacidades de significação por meio de produções empíricas e autênticas do gênero textual literário borror short story. Além disso, destacamos que se trata do recorte de uma dissertação de mestrado (SOUZA, 2015), e assim, a análise de capacidades de significação será feita a partir de aspectos relacionados à atividade praxiológica, com base nas descrições prévias do trabalho citado, que se alia a operação de (re)conhecimento da sócio-história (7CS) : (a) como elementos de ordem ideológica; (b) de ordem sociocultural do gênero borror short story; (c) em sintonia com a temática geral do gênero confrontada com as representações materializadas no corpus deste estudo. 
Com relação ao contexto, este estudo trata da análise de duas produções do gênero em pauta, que advêm de diferentes espaços sociais. A primeira, trata-se de um texto sem título realizado por um(a) aluno(a) (doravante A1) de nível básico de língua inglesa, de uma turma de $9^{\circ}$ ano, numa escola da cidade de Guarapuava, estado do Paraná. Esse texto corresponde a uma produção inicial (DOLZ; NOVERRAZ; SCHNEUWLY, 2004) requisitada por Souza em 2014, em meio à condução de um projeto de mestrado com enfoque no ensino da escrita de horror short stories (SOUZA, 2015).

Nessa conjuntura, como atividade final das duas primeiras aulas geminadas (de um conjunto de 8 aulas), a produção inicial de A1 resultou das seguintes questões tratadas por Souza: (a) levantamento de características gerais do gênero borror short story; (b) leitura e compreensão do texto The Demon at the Door; (c) retomada e contraste, em forma de discussão, sobre características inicialmente levantadas e aquelas presentes em The Demon at the Door, desde o contexto de produção até o nível enunciativo; (d) trabalho com o conteúdo temático do gênero citado; (e) amostra e discussão sobre possíveis temáticas de horror para produção inicial, como "acontecimento sinistro e inexplicável, fantasmagoria, casa condenada por espíritos, porões assombrados, pessoas possuídas, criaturas grotescas, acidentes domésticos inexplicáveis e desaparecimentos inexplicáveis" (SOUZA, 2015, p. 78 79). A escolha da produção inicial de A1, em detrimento das produções de outros alunos, se dá pela pertinência da escrita com relação à operação de reconhecimento da sócio-história do gênero, discutida neste estudo.

A segunda produção analisada, que será contrastada com o texto de A1, compreende a obra acanônica The Demon at the Door, assinada por Angel (pode tratarse de um pseudônimo), publicada abertamente no sítio "horrorstories.anthonet. com", intitulado World Horror Stories. A escolha desse texto justifica-se por sua utilização na apresentação inicial do projeto, e, consequentemente, nas práticas de ensino que embasaram a produção inicial de A1. A autorização para utilização do texto de A1, para fins de publicação de pesquisa, advém da dissertação de mestrado de Souza (2015), aprovada no Comitê de Ética conforme número CAAE 31611214.0.0000.0106 apresentado na Plataforma Brasil.

\subsection{Operação analisada das capacidades de significação}

Avaliamos o processo de escrita em relação à operação de linguagem (7CS) que deveria ser contemplada na produção inicial de A1. Ressaltamos que a discussão sobre essa operação está pautada, a saber: (a) no retrato de valores, 
normas e conceitos adotados no mundo social, e, (b) em sua relação com a atividade praxiológica a que pertence.

Com isso em mente, apresentamos os sintagmas textuais utilizados para categorizar a operação de linguagem 7CS como critérios de ensino e aprendizagem, os quais sistematizam, organizam e subsidiam a construção e a avaliação textual. Dessa forma, atentamo-nos para a descrição mais detalhada do conceito ideológicodiscursivo adotado neste espaço, bem como sobre a representação do campo sóciohistórico-cultural em relação à estabilidade do arquitexto do gênero horror short story e da temática geral do horror e seus efeitos sobre a atividade geral que o materializa.

Com relação à análise de elementos ideológicos e socioculturais, pautamonos numa condição contextual e dialógica que a natureza das palavras exerce (BAKHTIN/VOLOCHÍNOV, 2009), e, desse modo, verificamos sua utilização com relação à orientação temática geral, o que pode envolver, inclusive, a representação de outros gêneros de texto. Ainda sob esse aspecto, ressaltamos que a orientação temática geral não deve ser vista como sinônimo de coerência temática, pois esta última pressupõe a ação de linguagem propriamente, correspondente às capacidades de ação, diferentemente da primeira, a qual corresponde à atividade geral e às capacidades de significação, sobre as quais consideramos a semiose advinda das representações sócio-históricas do gênero.

\section{ANÁLISE DOS DADOS}

A premissa inicial tomada como ponto de análise da produção escrita do gênero borror short story parte de um movimento didático que envolve compreender quais capacidades de significação e respectivas operações de linguagem são necessárias para essa prática. Em meio a esse processo, apresentamos o modo como essas operações externas ao gênero textual podem ser analisadas por meio de marcas no texto. Para isso, o que propomos é a construção de séries de descrições sobre os critérios de análise das capacidades de significação.

Dada essa questão inicial, levamos em conta que a representação do trabalho docente acerca da escrita pautada em fatores ideológicos e sócio-históricos denota, num primeiro momento, dificuldades que variam desde a compreensão sobre o modo como é constituída essa esfera macrocontextual que é externa ao gênero e se relaciona com elementos transversais e de planificação, até a conotação que se deve dar aos itens linguísticos tomados como objetos dessa análise da atividade geral. Assim, em consideração ao nosso enfoque em borror short stories e o recorte elaborado sobre as capacidades de significação para discussão neste artigo, elencamos os 
elementos constituintes da esfera da produção escrita, com vistas na operação de (re)conhecimento da sócio-história do gênero textual (CRISTOVÃO; STUTZ, 2011), a qual foi analisada em dois textos de alunos de uma turma de $9^{\circ}$ ano.

Ressaltamos que a análise de operações linguageiras de nível macrocontextual depende da unidade de comunicação para ter efeito, e, embora essa prática aconteça individualmente sobre cada uma dessas operações, devem ser compreendidas numa natureza de interdependência com o texto, conforme será apresentado.

\section{1. (Re)conhecimento da sócio-história do gênero nas capacidades de significação}

O (re)conhecimento da sócio-história do gênero (doravante $7 \mathrm{CS}^{8}$ ) é uma operação de linguagem que abrange "apoio no arquitexto" (SOUZA, 2015, p.143), ou seja, nas formas de representação da linguagem em eventos sociais e seus efeitos de comunicação em momentos e espaços anteriores, que orientam ou contribuem para o formato atualizado do gênero que se reconhece. Na produção escrita, 7CS é uma operação de tomada de consciência sobre a materialização de normas, valores e regras do mundo social (STUTZ, 2012) imbricados no gênero em discussão, concernentes às representações que servem como ponte à imagem dada pelos alunos escritores em suas histórias mediante a subjetividade que os alicerça.

Um meio de análise sobre 7CS proposto neste estudo é a representação de efeitos comunicativos utilizados de forma consciente do léxico, constituído ideologicamente pela temática da atividade geral. Entendemos que esse enfoque é mais abrangente do que o olhar para o significado contextual do léxico, bem como para o tema enquanto componente impulsor-comunicacional específico da atividade de linguagem imediata, pois consideramos o aspecto diacrônico de sua natureza que envolve sopesar valores, normas e regras, como bem mencionados, os quais se sobrepõem à situação específica de comunicação, pairando num nível cultural (CRISTOVÃO, 2013) que permeia o gênero de texto.

É evidente que, por um lado, esse tipo de análise envolve o conhecimento na íntegra sobre as discussões realizadas na situação de ensino, para que se possa compreender as escolhas materializadas na produção dos alunos. De outro lado, é possível inferir as questões anteriormente apresentadas e efetuar uma análise pautada nesses critérios, tendo em mãos as produções dos alunos e o arquitexto dado como base para tanto. No intuito de ilustrar essas questões, observemos no

8. Optamos por manter a mesma sigla descrita por Cristovão e Stutz (2011) para o reconhecimento da sócio-história do gênero na proposta das capacidades de significação. 
quadro descritivo um trecho da obra de A1, sem título, e, como âncora de análise e discussão vejamos parte da obra The Demon at the Door, a qual foi utilizada como ferramenta de ensino para amostra inicial do gênero e para o esclarecimento sobre o problema de comunicação (ver DOLZ; NOVERRAZ; SCHNEUWLY, 2004):

Quadro 2. (Re)conhecimento da sócio-história.

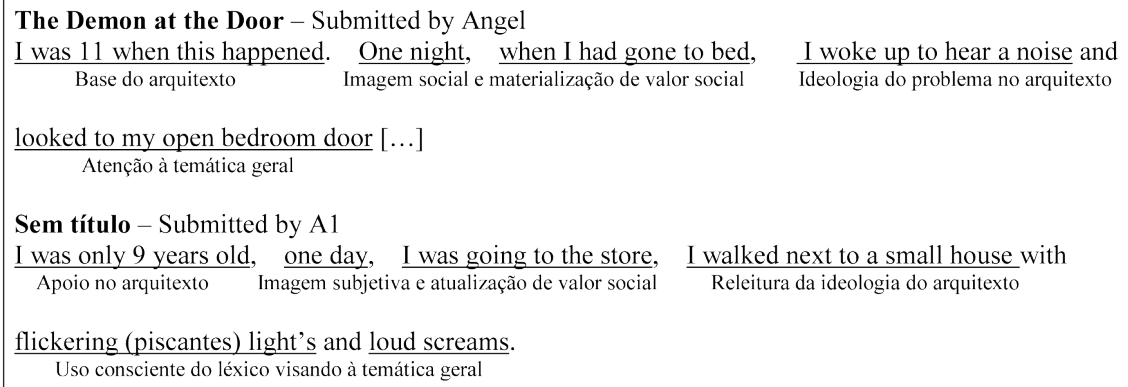

Fonte: Adaptado de Souza (2015, p. 143-144).

Com base nos excertos, constatamos que um dos mecanismos de análise da operação 7CS pode ser verificado por meio de sintagmas e de suas denotações enquanto constituintes da escrita. Essa questão pode ser ilustrada ao contemplarmos o segmento inicial utilizado por A1, o qual notoriamente exerce a mesma função introdutória do narrador em primeira pessoa, conforme ocorre em The Demon at the Door. Nesse sentido, o sintagma verbal "I was", recorrente em ambas as obras, expressa o diálogo entre um elemento que paira no arquitexto do gênero borror short story, mobilizado por A1, num movimento de construção sociossubjetiva. Por sua vez, essa construção remonta à figura do narrador como fulcro do processo de desenvolvimento da narrativa, direcionando ao personagem delator dos acontecimentos toda a carga de ações que constituem a progressão do gênero em debate.

Do mesmo modo, na utilização do sintagma nominal "one day", A1 estabelece uma transposição da imagem social "one night", que refrata a atmosfera onde se observa a gênese do desenvolvimento e propagação do sobrenatural. Nessa transposição, A1 assinala um movimento de construção sociossubjetiva e, por conseguinte, consciência sobre $7 \mathrm{CS}$, pois, pelo que se pode perceber, este autor troca intencionalmente o marcador temporal e ideológico (night) utilizado na criação da atmosfera do horror por Angel, no intuito de seguir uma hierarquia similar ao 
jogo de sintagmas descritos em The Demon at the Door, mas de forma atualizada, voltada à amplitude do espaço-tempo (day/o dia).

O mecanismo que viabiliza a verificação do domínio sobre 7CS trata da materialização de um valor social, quando um determinado sintagma atribuirá o peso de uma progressão ou atualização das construções coletivas, sobretudo, no que diz respeito à delimitação do tempo e do espaço em que a narrativa se desenvolve. Sob as lentes do interacionismo sociodiscursivo, por exemplo, essa análise pode ser feita a partir de segmentos de orientação temática (BRONCKART, 2008). No entanto, tais segmentos correspondem à construção da unidade de comunicação utilizada na atividade de linguagem imediata, e, em nosso caso, o enfoque recai sobre a ciência da representação geral.

Isso posto, entendemos que o valor social empregado em The Demon at the Door corresponde à junção entre o espaço ideológico pertinente à criação do medo, caracterizado pelos itens lexicais "bed" e "bedroom door", e, pelo efeito negativo esperado pelo sintagma verbal em tempo disjunto "I bad gone", resultando num segmento de orientação temática geral e de valor social, no qual insere-se uma ponte para o desenvolvimento da problemática e de seu efeito de sustentação do medo e do horror.

Esse formato reverenciado na elaboração da escrita nutre um elemento importante para compreendermos o funcionamento da operação $7 \mathrm{CS}$, e, como consequência, o suporte das bases da sócio-história do gênero borror short story: a construção cultural e suas relações com a orientação temática geral. Para que o gênero tratado alcançasse o patamar literário que ocupa na instância atual, e, para que os sintagmas descritos acima reflitam, de fato, as proposições feitas neste estudo, comunidades literárias (escritores, filósofos da composição, críticos e pesquisadores) se enfrentam historicamente numa guerra discursiva pela liderança e domínio de seus tipos utopicamente homogeneizados e defendidos de padrão textual. Todavia, o gênero de texto é um artefato dinâmico, e, por essa razão, atende tanto às tentativas sociais de padronização como àquelas que causam ruptura.

Um exemplo clássico disso que expusemos é o consumo mundial de textos dos variados gêneros criados por Edgar Allan Poe. Em diversos momentos de sua vida, o autor foi privado do essencial para subsistência ao enveredar-se por uma estética de escrita veementemente condenada pela crítica literária de sua época, recebendo ligeiro reconhecimento apenas nos últimos anos antes de sua morte. Porém, em tempos atuais, Poe é um dos autores dignos de inúmeras republicações, traduções e adaptações disputadas por editoras em várias partes do mundo. Dentre vários destaques, centramo-nos em obras conhecidas como short stories (contos) na 
literatura vigente. Em meados de 1840 e 1845, Poe (1999) desenvolveu a própria filosofia da composição, visando derrubar paredes do modo clássico como o gênero tale $^{9}$ (conto) era produzido. Seus textos variaram entre ficção científica, mistério e loucura (RIOS-REGISTRO; CRISTOVÃO, 2009/2010), mas sua marca foi emplacada na morte e seus textos na promoção do horror (PAES, 2017).

Assim, elucidamos que a relevância cultural de um texto vai depender da aceitação ou da refutação por membros da comunidade à qual ele se destina. Agregada a essa questão, a denominação implicada ao gênero acompanhará valores estético-composicionais que correspondem ao modo como determinados grupos sociais encaram um dado texto. Desse modo, o (re)conhecimento da sócio-história de um gênero textual exige a valoração de sua implicação cultural, como ocorreu com diversos dos textos escritos por Poe. Sua arte dirigiu-se à criação de tales, dignos de uma filosofia da composição especialmente redigida pelo autor. Contudo, sua proposta da unidade de efeito e a elementarização de assertivas de profundidade psicológica foram importantes para, ao mesmo passo, excitar o público e controlar melhor a arte em uma "narrativa em prosa curta" (HUBBLE, 1996), representando, desse modo, a chave mestra para a abertura de um espaço no meio literário que apresentou a quebra de paradigmas de escrita, concebida pela terminologia short story.

Essa representação cultural estende-se à adjetivação que incide sobre o gênero por meio de orientações temáticas gerais, como ocorreu sócio-historicamente com tale, pelas configurações fairy tale, folk tale, tall tale, trickster tale e pourduoi tale, para citar alguns. No caso de short story, tratamos aqui da identidade do horror e, à vista disso, vislumbramos em nossas discussões o gênero textual horror short story tomado como objeto de ensino e que, mesmo em publicações não tão recentes, denomina e fortalece a arte de tales desenvolvidos por Poe (MARLER, 1979).

Assim sendo, o (re)conhecimento da sócio-história de um gênero pode ser averiguado pelo ato de se fomentar, na atividade de linguagem na qual consolidase a delimitação do tema (CRISTOVÃO, 2013), uma orientação temática geral, interpelada pela ideologia e pela tentativa de representação textual como componentes culturais. $\mathrm{Na}$ obra de $\mathrm{A} 1$, a orientação temática geral do horror é

9. Ambas as terminologias são utilizadas para se falar de conto. Entretanto, tale é o termo predecessor a short story, imbuído de certas características que são atualizadas no modo de se construir uma narrativa nesse segundo gênero textual, sobretudo, nas obras de Poe. No entanto, essa distinção apareceu de forma explícita postumamente aos trabalhos desse autor, quando a crítica literária reconheceu a importância cultural dessa arte. A distinção entre tale e short story pode ser revista em Marler (1974). 
configurada por um núcleo conflituoso, delimitado mediante a utilização dos sintagmas verbais e nominais "I was going to the store" $\mathrm{e}$ "I walked next to a small house".

No entanto, esse núcleo propulsor da problemática que desenrolará o horror não é suficiente por si só para delimitarmos a condição da temática geral, mas a representação cultural que esse núcleo denota agregado às unidades de ação (CARROLL, 1990/2004). Além do aspecto exponencial da criação do horror na orientação da temática geral, a construção da unidade de efeito (POE, 1999) também ratifica a base sócio-histórica do gênero borror short story, criada na articulação entre as unidades de ação e o núcleo conflituoso.

\section{CONSIDERAÇÕES FINAIS}

Este estudo demonstrou que as capacidades de significação representam uma variável importante em termos epistemológicos para o entendimento do funcionamento da linguagem em sua relação com os gêneros e seus aspectos externo-macrotextuais. Além disso, por situarem-se na construção e compreensão das representações de valor social, histórico e ideológico da atividade geral do ser humano, foi possível perceber que influenciam na forma como o mundo social é materializado, bem como a linguagem é capaz de interconectar os diferentes sentidos estabelecidos por sua natureza semiótica e fundamental para a expressão humana em suas formas de agir.

Assim, parte das operações psíquicas da significação compreendem tanto a inteligibilidade da sócio-história dos gêneros textuais quanto a compreensão das construções coletivas. Esses elementos, ainda sob a ótica epistemológica, encontramse supraconectados aos arquétipos discursivos mobilizados pelas atividades de linguagem imediatas, o que significa pensarmos em efeitos de comunicação que eventos anteriores ao espaço-tempo situacional podem gerar, em representações consubstanciadas no discurso, no arquitexto como modelo discursivo base para as relações dialógicas, na materialização das normas, regras e valores implicados no sujeito em seu agir comunicativo.

Do ponto de vista didático, as capacidades de significação, pelas análises efetuadas neste estudo, permitem o reconhecimento da construção ideológica textual, da representação dos saberes coletivos, dos valores semióticos e da negociação entre indivíduos para as diferentes orientações para a realidade. Compreendemos que a operacionalização das capacidades de significação, juntamente com as capacidades de ação, discursivas e linguístico-discursivas podem potencializar a relação entre os indivíduos que se apropriam da linguagem para 
significar no mundo e as representações que desejam efetivar, como no caso das produções escritas estudadas.

Para o professor de língua inglesa, este texto pode contribuir para intensificar a gama de recursos avaliativos necessários para o ensino de gêneros textuais, capazes de tornar mais lúcida a concepção de significação. A partir disso, é possível proporcionar uma visão mais próxima das representações gerais da atividade humana, bem como sua implicação no ensino de produção ou até mesmo de compreensão textual, que não permanecem de forma alguma no nível mais superficial do texto, mas demandam compreensão profunda do funcionamento da linguagem.

Por fim, para pesquisadores e interessados no estudo da linguagem, nossa contribuição visa ampliar o reconhecimento dos elementos externo-macrotextuais dispostos até o momento na literatura vigente, demonstrando que o processo de significação envolve a interconexão entre sentidos, o simbolismo, o apoio nos arquitextos e as ligações intertextuais, as representações, a estruturação do corpo ideológico-discursivo e a consciência de produtos culturais que imprimem suas próprias marcas. Contudo, esta pesquisa não elimina a complexidade das capacidades de significação, nem esgota as possibilidades de se efetuarem mais análises, haja vista o espaço aqui destinado, além dos inúmeros gêneros textuais e as múltiplas atividades de linguagem que poderão mobilizar diferentes operações não apresentadas neste instante.

\section{$\overline{\text { REFERÊNCIAS }}$}

BAKHTIN, M. M. / VOLOCHÍNOV, V. N. (1973/2009). Marxismo e filosofia da linguagem. Trad. Michel Lahud e Yara Frateschi. 13 ${ }^{\mathrm{a}}$ ed. São Paulo: Hucitec.

BRASIL. (2018). Base Nacional Comum Curricular. Secretaria de Educação Básica. Brasília: MEC/SEB.

BRONCKART, J. P. (1987). Interactions, discours, significations. In: Langue Française. n. 74, p. 29-50. Disponível em https://archive-ouverte.unige.ch/unige:37348. Acesso em 18 de setembro de 2018 .

BRONCKART, J. P. (1999). Atividade de linguagem, textos e discursos. Por um interacionismo sociodiscursivo. Tradução de Anna Rachel Machado, Péricles Cunha. São Paulo: EUDC, 1999.

BRONCKART, J. P. (2004). Les genres de textes et leur contribution au développement psychologique. In: Langages: Les genres de la parole, n.153, pp. 98-108. 
BRONCKART, J. P. (2006). Atividade de linguagem, discurso e desenvolvimento bumano. Tradução de Anna Rachel Machado, Maria de Lourdes Meirelles Matencio. Campinas, SP: Mercado de Letras.

BRONCKART, J. P. (2008). O agir nos discursos: das concepções teóricas às concepções dos trabalhadores. Tradução de Anna Rachel Machado, Maria de Lourdes Meirelles Matencio. Campinas, SP: Mercado de Letras.

BRONCKART, J. P. (2016). Pourquoi et comment devenir didacticien? Presses Universitaires du Septentrion, v. 1, n. 38 .

CARROLL, N. (2004). The philosopby of borror or paradoxes of the beart. New York, New York: Routledge - Taylor and Francis e-Library.

COSTA-HÜBES; T. C.; SIMIONI, C. A. (2014). Sequência didática: uma proposta metodológica curricular de trabalho com os gêneros discursivos/textuais. In: BARROS, E. M. D. de; RIOS-REGISTRO, E. S. (Orgs.). Experiências com sequências didáticas de gêneros textuais. Campinas, SP: Pontes Editores, pp.15-40.

CRISTOVÃO, V. L. L. (2007). Modelos didáticos de gêneros: uma abordagem para o ensino de língua estrangeira. Londrina: EDUEL.

CRISTOVÃO, V. L. L. (2009). A relação entre teoria e prática no desenvolvimento do professor. In: Magalhães, M. C. C. A formação do professor como um profissional crítico: linguagem e reflexão. $2^{\text {a }}$ ed. Campinas, São Paulo: Mercado de Letras, pp. 179-198.

CRISTOVÃO, V. L. L. (2013). Para uma expansão do conceito de capacidades de linguagem. In: BUENO, M. A.; LOPES, P. T.; CRISTOVÃO, V. L. L. (Org.). Gêneros textuais e formação inicial: uma homenagem à Malu Matencio. Campinas: Mercado de Letras, pp. $357-383$.

CRISTOVÃO, V. L. L; STUTZ, L. (2011). Sequências Didáticas: semelhanças e especificidades no contexto francófono como LI e no contexto brasileiro como LE. In: SZUNDY, P. T. C. et al. (org.). Linguística Aplicada e Sociedade: ensino e aprendizagem de línguas no contexto brasileiro. Campinas: Pontes Editores, pp. 17-40.

CRISTOVÃO, V. L. L. (2015). Gêneros textuais no ensino-aprendizagem e na formação do professor de línguas na perspectiva interacionista sociodiscursiva. Lucas Moreira dos Anjos-Santos, Ana Paula Marques Beato-Canato, Gladys Plens de Quevedo Pereira de Camargo (orgs). Campinas, São Paulo: Mercado de Letras. 
DOLZ, J.; NOVERRAZ, M.; SCHNEUWLY, B. (2004). Sequências didáticas para o oral e a escrita: apresentação de um procedimento. In: SCHNEUWLY, B.; DOLZ, J. Gêneros orais e escritos na escola. Trad. e org. Roxane Rojo e Glaís Sales Cordeiro. Campinas, SP: Mercado de Letras.

DOLZ, J.; PASQUIER, A.; BRONCKART, J. P. (1993). L'acquisition des discourse: emergence d'une competence ou aprentissage de capacities langagières? Études de Linguistique Appliquée, n. 92, pp. 23-37.

ÉRNICA, M. (2008). Le développement humain chez Vygotskij: Pensée et Langage réexaminé sur la base des écrits de 1925. Cabiers de l'ILSL, n. 24, pp. 43-58.

Glossário CEALE (Centro de Alfabetização, Leitura e Escrita). (2014). Disponível em: http://ceale.fae.ufmg.br/app/webroot/glossarioceale/verbetes/sentido-significadoe-significacao. Acesso em 02 de setembro de 2018.

HUBBLE, J. (1996). Here we are now, Entertain us: Poe's contributions to the short story. Disponível em: http://geocities.jeremyhubble.com/poe.html. Acesso em 12 de abril de 2018.

KING, S. (2014). A coisa. Rio de Janeiro: Editora Suma de Letras. Tradução de Regiane Winarski.

MACHADO, A R. (2005). A perspectiva interacionista sociodiscursiva de Bronckart. In: MEURER, J. L.; BONINI, A.; MOTTA-ROTH, D. Gêneros: teorias, métodos, debates. São Paulo: Parábola Editorial, pp. 237-259.

MACHADO, A. R.; CRISTOVÃO, V. L. L. (2009). A construção de modelos didáticos de gêneros: aportes e questionamentos para o ensino de gêneros. In: ABREUTARDELLI, L. S; CRISTOVÃO, V. L. L (Orgs.). Linguagem e educação: o ensino e a aprendizagem de gêneros textuais. Campinas: Mercado de Letras, pp. 123-151.

MARLER, R. F. (1974). From tale to short story: the emergence of a new genre in the 1850’s. American Literature, v. 46, n. 2, may, pp. 153-169. Disponível em: http://www. jstor.org/stable/2924690. Acesso em: 11/11/2010.

PAES, J. P. (2017). Edgar Allan Poe, História Extraordinárias. Seleção, apresentação e tradução de José Paulo Paes. $1^{\text {a }}$ ed. São Paulo: Companhia das Letras.

PARANÁ, SEED. (2008). Diretrizes Curriculares de Lingua Estrangeira para o Ensino Fundamental. Secretaria de Estado de Educação do Paraná, Superintendência da Educação. 
POE, E. A. (1999). Poemas e Ensaios. Tradução de Oscar Mendes e Milton Amado. $3^{\text {a }}$ ed. São Paulo: Globo.

RIOS-REGISTRO, E. S.; CRISTOVÃO, V. L. L. (2009/2010). The Short Story: an analysis perspective for the teaching of English. Journal of Teaching and Research in English Literature - Special Issue, n.p.

SCHNEUWLY, B. (2004). Gêneros e tipos de discurso: considerações psicológicas e ontogenéticas. In: Gêneros orais e escritos na escola. Trad. e org. Roxane Rojo e Glaís Sales Cordeiro. Campinas, SP: Mercado de Letras, pp. 19-34.

SCHNEUWLY, B.; DOLZ, J. (1997). Les genres scolaires. Des pratiques langagières aux objets d'enseignement. In: Repères, recherches en didactique du français langue maternelle. Pratiques langagières et enseignement du français à l'école, n. 15, pp. 27-40.

SOUZA, E. G. G. de. (2015). Horror short stories nas aulas de língua inglesa: transposição didática em análise. 279f. Dissertação (Mestrado em Letras) - Universidade Estadual do Centro-Oeste, Guarapuava/PR.

STUTZ, L.; CRISTOVÃO, V. L. L. (2011). A construção de uma sequência didática na formação docente inicial de língua inglesa. SIGNUM: Estud. Ling., Londrina, n. 14/1, jun., pp. 569-589.

STUTZ, L. (2012). Sequências didáticas, socialização de diários e autoconfrontação: instrumentos para a formação inicial de professores de inglês. 2012, 383f. Tese (Doutorado em Estudos da Linguagem) - Universidade Estadual de Londrina.

VYGOTSKY, L. S. (1987/2008). Pensamento e Linguagem. Tradução de Jefferson Luiz Camargo. $4^{\mathrm{a}}$ ed. São Paulo: Martins Fontes.

WERTSCH, J. V. (1988). Vygotsky and the Social Formation of Mind. Cambridge, Massachusetts: Harvard University Press.

Recebido: 4/06/2019

Aceito: 22/09/2019

Publicado: 2/10/2019 